Open Access

\title{
Exploring quality and its value in the Italian olive oil market: a panel data analysis
}

\author{
Anna Carbone, Luca Cacchiarelli ${ }^{*}$ and Valentina Sabbatini
}

\author{
* Correspondence: \\ cacchiarelli@unitus.it \\ Università degli Studi della Tuscia, \\ Viterbo, Italy
}

\begin{abstract}
Olive oil markets, both traditional and new ones, are changing rapidly with vertical as well as horizontal differentiation that increasingly play a role in featuring demand and supply. The paper explores the role and effectiveness of different quality clues in the creation of value in high segments of the Italian olive oil market by applying a hedonic price model. Data come from one of the oldest and most reputed Italian guides Flos Olei which reviews around 250 Italian producers and their products. The study covers three production years (from 2012 to 2014) so that, besides the OLS estimations, a panel data analysis is also conducted. Main results indicate that consumers give value to features directly related to the product, as well as to the raw material used and to the production process; also, the kind of producer and the production area affect price. Moreover, the analysis shows the emerging role of experts in releasing valuable information about quality. On the contrary, European quality schemes, such as those for product origin and for organic production, do not bring additional value to consumers in the explored high market segments.
\end{abstract}

Keywords: Flos Olei olive oil guide, Quality clues, Hedonic price model, OLS, Panel regression

JEL code: D12, Q13

\section{Background}

Europe produces about two thirds of the worldwide olive oil production with a high share of the remaining volumes coming from the other countries of the Mediterranean basin (IOOC: International Olive Oil Council 2016). Italy follows Spain, the first world producer in terms of volumes, with an average $20 \%$ of the total European olive oil production. About two thirds of total Italian production is represented by extra virgin olive oil (EVOO). In many traditionally producing countries, the cultivation of olive trees is widespread almost all over the country and involves the majority of the farms. Olive mills are often small and technologically simple processing units with a local basin of olive suppliers and clients. However, also larger and more technological processing plants, both private and cooperative, are active in the market and supply different demand segments.

The main olive oil producer countries of the Mediterranean basin also represent the most traditional consumers, absorbing almost half of the world's olive oil production. In these countries, until recent years, olive oil has been considered almost a

(c) The Author(s). 2018 Open Access This article is distributed under the terms of the Creative Commons Attribution 4.0 International License (http://creativecommons.org/licenses/by/4.0/), which permits unrestricted use, distribution, and reproduction in any medium, provided you give appropriate credit to the original author(s) and the source, provide a link to the Creative Commons license, and indicate if changes were made. 
commodity with few relevant quality features driving the market. In this context, local informal markets have remained widespread; for example, in Italy, direct sales still represent nowadays about one third of olive oil family purchases (AGER 2016). Consumption habits traditionally act as a major orientation tool for consumers and are still important in these countries (Carbone et al. 2014). In fact, as olive oil is a condiment used together with many other foods, its taste is somehow pervasive so that consumers are acquainted to the specific taste of the olive oil they use. In such local markets, quality variability over time and space is accepted as a "natural" consequence of the plant physiology of the olive tree. Besides these local markets, more recently, large retailers have become an important channel for olive oil (AGER 2016; Marchini et al. 2015; Stasi et al. 2012). Here, olive oils from larger and more industrialized producers can be found; these deliver a more standardized product that often stems out from mixing up oils coming from different areas/countries.

In recent years, olive oil consumption is spreading to non-traditional areas of the world, from northern European countries to the American continent and almost everywhere where there are wealthy consumers willing to pay for a more expensive substitute of other vegetable oils. Olive oil is appreciated for its taste, nutritional properties, and positive impact on landscape and environment and as part of the traditional Mediterranean rural heritage.

However, both traditional and new markets have changed and are still changing rapidly, with both vertical and horizontal differentiations that play a role in featuring the market (Carbone et al. 2014). Many credence attributes are also becoming important in the consumers' eye and need assessment especially in countries where olive oil has recently been introduced and consumers lack expertise to correctly evaluate quality (Cabrera et al. 2015; Matthäus and Spener 2008; Romo Munoz et al. 2015). In areas where local traditional markets are relevant and in touristic areas, on-farm sales allow for face-to-face relationships and endorsement. However, small producers, deeply rooted in the place where they produce, with low capability to invest in communication tools and hence enjoying low visibility in further markets, nowadays may rely on their own website and on social networks and apps where experts and journalists become key communicators together with other, more or less, experienced consumers (Dentoni and Reardon 2010).

Based on these premises, the paper seeks at exploring the role of different quality clues in the creation of value in high segments of the Italian olive oil market. A hedonic price model has been estimated where price is explained by different quality clues. Despite the relevance of the olive oil sector, only a few works have been devoted to assessing the most effective quality clues, although their number is noticeably increasing in recent years (Cabrera et al. 2015; Cacchiarelli et al. 2016; Karipidis et al. 2005; Romo Munoz et al. 2015; Gázquez-Abad and Sánchez-Pérez 2009; Roselli et al. 2016; Diotallevi 2010). The analysis here presented covers the EVOOs included in the oldest and most reputed Italian guide Flos Olei which each year reviews around 250 producers and their products coming from all Italian regions. The study covers three production years: 2012, 2013, and 2014. This allows to use both the OLS and a panel data model. The last may be considered the most original part of the work as to the authors' knowledge no published paper so far employed hedonic price models based on panel data with reference to the olive oil market. 
The remainder of the article is organized as follows: the "Background" section provides a discussion on relevant and emerging quality features in the olive oil market. The "Methods" section is devoted to presenting the methodology and the source of data, while the results are discussed in the "Results and discussion" section. Some concluding remarks are condensed in the "Conclusions" section.

\section{Emerging quality attributes in the EVOO market}

Olive oil is no longer a commodity or even a weakly differentiated good. It has largely become diversified and sophisticated with many features whose relevance is arising, including cultural and hedonic contents. In addition, olive oil is today acknowledged for its nutritional and health benefits as well as for having diverse positive environmental impacts in the tree cultivation stage (Cacchiarelli et al. 2016).

In this changing market, the production area remains a major factor for market segmentation and acts as an effective quality clue (Van der Lans et al. 2001; Fotopoulos and Krystallis 2001). The relevant clues related to the geographical roots of olive oil are diverse: (i) the country of origin may be reported on the label, according to different national rules (in Italy, it is mandatory); (ii) the macro-area (in Italy, there are substantial differences in volumes, quality, and reputation among Southern, Central, and Northern macro-areas even if information on this does not appear in the label) (Aprile et al. 2012); (iii) the region, that in some case is well renowned and highly reputed (i.e., Tuscany whose olive oil is worldwide famous) while in other cases is emerging, such as Abruzzo or Lazio (sometimes the label discloses the region of production even if in different ways and with different degrees of visibility); (iv) geographical indications (GI) such as protected designation of origin (PDO) and protected geographical indications (PGI) that may coincide with entire regions but, more often, refer to smaller and more homogeneous areas (i.e., Riviera Ligure, Sabina). Product origin is related to the place of production due to climate and other natural features, including tree varieties as well as production techniques and related traditions. The GI certifications enhance both vertical (e.g.: certified vs non-certified oils) and horizontal (e.g.: different PDOs or PGIs) differentiation by connecting product characteristics with the place of origin (Carbone et al. 2014).

Chemical and physical features (i.e., acidity or polyphenols) are traditionally relevant in differentiating olive oils with respect to taste and nutritional properties. These features basically stem from the plant variety, the cultivation and harvesting techniques, as well as from the processing technology (De Gennaro et al. 2009). In particular, the acidity content remains the most relevant element for vertical differentiation in the olive oil market. According to this aspect, olive oils are classified as extra-virgin, virgin, and fine olive oils (IOOC: International Olive Oil Council 2016).

As for the olive varieties, these also affect the organoleptic characteristics of the oil. Traditionally, olive oils are made out of blends of all the olive varieties that are present in each farm. More recently, the milling technology and machinery allow for milling separately even small quantities of olives. Hence, monovarietal oils are gaining momentum allowing for further segmenting the market and are now trendy in high market niches (Cacchiarelli et al. 2016). Since some olive varieties are widely present in different environments while others are confined in smaller areas, the varieties used 
add role for the place of origin of the product as a mean of diversification and act as a source of information on different aspects of product quality. Remaining on taste, the addition of flavorings (i.e., truffle, rosemary, basil, hot pepper, lemon) is increasingly used in product diversification and it is appreciated by consumers as a way of easily adding taste to both simple and sophisticated recipes (Karipidis et al. 2005).

Consumers may also look at the way olives are harvested and milled and, more recently, use the organic certification as a mean for inferring information on product safety and environmental impacts; notwithstanding, evidences on the effectiveness of this strategy for differentiating and increasing product value are mixed as it will be discussed in the "Results and discussion" section.

Consumers also look at product appearance to infer information on attractiveness and sensorial quality. As for the color, this is related to the maturation of olives and to the amount of leaves that are milled and usually goes from pale yellow to emerald green. Also, transparency matters. In particular, non-filtered turbid oils meet an increasing appreciation, as it is witnessed by the increasing number of such claims in the marketplace.

Last, also the bottle plays a relevant role with its size, shape, material, and color, together with the design of the label and the information released (Karipidis et al. 2005; Romo Munoz et al. 2015; Cabrera et al. 2015).

At home as well as in restaurants, it is now likely to find a choice of different olive oils for pairing with different food preparations. As a consequence, it can be said that habits as consumption drivers are, to some extent, being replaced by appreciation for variety and by curiosity for new products.

Summing up, it is important to pinpoint that, as the sophistication of the product and the complexity of the market increase, additional information is required and its effectiveness and reliability can be questioned (Hassan and Mornier-Dilhan 2002). Following a well-established practice of the wine market, both intermediate buyers and final consumers increasingly seek for different sources of information such as direct knowledge of the producers, friends' words of mouth, blogs, reviews, and evaluations by experts-both in journals and guides-testing events, and prizes (Paroissien and Visser 2018; Cacchiarelli et al. 2016). In line with this general tendency, also, restaurants no longer serve olive oil in anonymous transparent bottles, as it used to be, but present labeled bottles that convey information and assess quality to exigent consumers.

\section{Methods}

Different methodological approaches have been used in economic literature in order to detect which olive oil features affect consumers' choices in differentiated product markets. For instance, some authors have tried to elicit consumers' preferences and willingness to pay through discrete choice models such as conjoint analysis and the random utility model (Del Giudice et al. 2015; Aprile et al. 2012; Scarpa and Del Giudice 2004). Other studies used experimental analysis (Delgado and Guinard 2011) and multicriteria methods (Sandalidou et al. 2002) or analyzed the sensory profiles of olive oil. Recently, there has been a growing interest in the use of the hedonic price method as a mean to estimate what attributes influence olive oil price (Cabrera et al. 2015; Romo Munoz et al. 2015; Cacchiarelli et al. 2016). 
In order to assess the relationship between price and the different quality clues of high-quality Italian olive oils, we estimate a hedonic price model. The theoretical development of the hedonic price model is based on the work of Rosen (1974), who affirms that the price of any product can be described as a function of its characteristics. Hence, by regressing price on product attributes, the hedonic function provides estimates of the influence of each attribute on the equilibrium price, embedding both supply and demand factors (i.e., production costs and consumers' willingness to pay) (Cacchiarelli et al. 2014; Costanigro et al. 2010; Smith et al. 2016).

An important aspect in the hedonic price equation concerns its functional form. In literature, various functional forms (log-log, log-linear, linear, and others) have been employed. The Ramsey RESET test ${ }^{1}$ on Flos Olei data indicates that the log-linear specification performed better than the other functional forms. Furthermore, the log-linear specification presents two advantages: (i) it allows obtaining residuals that are approximately normally distributed as required by the econometric models here used; (ii) the interpretation of the regression coefficients is more immediate: holding all other variables fixed, the dependent variable changes by $100 \times\left(e^{\text {coef }}-1\right)$ percent for a one-unit increase of one of the regressors. As a consequence, results are interpreted as the price premium (PP) associated to each feature (Thrane 2004; Schamel 2006). Specifically, the log-linear specification is expressed as follows:

$\log P=\alpha_{0}+\alpha_{1} M+\alpha_{2}$ Pro $+\alpha_{3} A r$

where the logarithm of the price $(P)$ of a bottle of olive oil is regressed on different quality clues which may be grouped in three categories: (i) $M$ includes variables assessing product characteristics; (ii) Pro groups variables related to the production process and the producer; and (iii) $A r$ includes variables expressing the production area and the certification of origin.

The analysis covers high-quality EVOOs from all Italian regions mainly produced by farms with on-farm mills or by small artisanal mills, while few oils in the sample are produced by cooperative mills. Data comes from one of the major Italian olive oil guides (Flos Olei, 2013, 2014, and 2015 editions that review oils from 2012, 2013, and 2014 harvesting years, respectively). The guide has been chosen for its well-established reputation and for the richness of information reported. It is worth noting that the sample is not representative of the whole Italian EVOO market but refers to the higher market segments where different quality features are relevant. Hence, evidences from this sample cannot be simply extended to the whole market. However, looking at these high segments provides insights on tendencies that will likely spread out in the wider market in the near future.

Since this study data cover olive oils included in selected guide for 3 years, a panel data analysis was also conducted. The main advantages of the panel data approach are (i) observing a sample in a temporal and dynamic dimension, (ii) getting information about past attitudes of the analyzed units, and (iii) increasing the size of the sample allowing more degrees of freedom and more sample variability (Gujarati 2004; Hsiao 2007).

Specifically, we run both the annual and pooled OLS estimations for the three considered years and a panel data analysis. Different panel data models were estimated: pooled ordinary least squares and random (RE) and fixed (FE) effects models. Pooled regression, assuming homogeneity for all olive oils, may lead to biased estimates due to 
a correlation between independent variables and unobservable effects. FE model introduces the olive oil specific effect, providing consistent estimates regardless of correlation between the specific effects and the independent variables. However, this approach does not permit to estimate the coefficients of the time-invariant variables such as regressors indicating the production areas. Finally, the RE method is based on the assumption that the unobserved specific effects of the olive oil are uncorrelated with the variables included in the regression (Greene 2003). As a consequence, an advantage of random effects is that time-invariant regressors can be included in the model. Different tests were employed to choose the panel data model that better fit the dataset. Firstly, the Breusch and Pagan Lagrangian multiplier test (Breusch and Pagan 1980) was performed in order to evaluate if there was significant difference between RE and pooled models. The result led to reject, at $1 \%$ of significance, the null hypothesis indicating that RE model is adapted better than the pooled one. Moreover, in relation to the choice between the RE and FE models, the Hausman (1978) test was performed. The $p$ value (greater than $0.05 \%$ ) brings us to accept the null hypothesis of the reliability of the RE model. As a consequence, the discussion of the results, reported in the "Results of the regressions" section, concerns mainly RE estimates. In addition, Breusch-Pagan/Cook-Weisberg and White tests and variance inflation factors have excluded the presence, respectively, of heteroskedasticity and multicollinearity.

\section{Results and discussion}

\section{The olive oil sample: descriptive statistics}

Descriptive statistics for the variables with which the model is built are presented in Tables 1 and 2 and discussed below.

1. The explained variable is consumer price (Euros/lt.) of each selected olive oil, referred to the producing country market (always Italy for us). ${ }^{2}$ As prices are referred to different bottle size $(250 / 500 / 750 \mathrm{ml})$, in order to allow proper comparisons, the dependent variable that here feeds the model is built based on the average value of each class transformed in Euros per liter.

Table 1 reports the descriptive statistics (i.e., minimum, mean, medium, the different quantiles and maximum) of the prices. ${ }^{3}$ The median price is 22 Euros/lt. for each of the three considered years, while the mean slightly increases from 22.75 to 23.2 Euros/ lt. The first decile of the distribution corresponds to 14 Euros/lt. while at the upper

Table 1 Price values and their distribution in the sample

\begin{tabular}{llll}
\hline & 2012 & 2013 & 2014 \\
\hline Min & 6.00 & 6.00 & 6.00 \\
Mean & 22.75 & 23.00 & 23.20 \\
10th quantile & 14.00 & 14.00 & 14.00 \\
30th quantile & 18.00 & 18.00 & 18.00 \\
50th quantile (median) & 22.00 & 22.00 & 22.00 \\
70th quantile & 27.00 & 27.00 & 27.00 \\
90th quantile & 33.00 & 36.00 & 33.00 \\
Max & 56.00 & 65.00 & 56.00 \\
\hline
\end{tabular}

Source: our elaborations on FLOS OLEl (editions 2013, 2014, and 2015) 
Table 2 Number of frequency of cases for the explanatory variables

\begin{tabular}{|c|c|c|c|c|c|c|c|c|c|}
\hline & \multirow[t]{2}{*}{ Variables } & \multicolumn{2}{|c|}{2012} & \multicolumn{2}{|l|}{2013} & \multicolumn{2}{|l|}{2014} & \multicolumn{2}{|c|}{3 years } \\
\hline & & $\overline{\text { Obs }}$ & $\overline{\text { Freq }}$ & $\overline{O b s}$ & $\overline{\text { Freq }}$ & Obs & $\overline{\text { Freq }}$ & Obs & $\overline{\text { Freq }}$ \\
\hline \multirow[t]{8}{*}{ Product attributes } & Light fruity taste & 21 & 8.8 & 25 & 9.3 & 16 & 6.2 & 62 & 8.1 \\
\hline & Medium fruity taste & 187 & 78.6 & 201 & 74.7 & 195 & 75 & 583 & 76 \\
\hline & Intense fruity taste & 30 & 12.6 & 43 & 16 & 49 & 18.8 & 122 & 15.9 \\
\hline & Bottle size 0.25 I & 12 & 5 & 17 & 6.3 & 18 & 6.9 & 47 & 6.1 \\
\hline & Bottle size 0.5 I & 217 & 91.2 & 243 & 90.3 & 235 & 90.4 & 695 & 90.6 \\
\hline & Bottle size 0.75 I & 9 & 3.8 & 9 & 3.3 & 7 & 2.7 & 25 & 3.3 \\
\hline & Local varieties & 172 & 72.3 & 178 & 66.2 & 169 & 65 & 519 & 67.7 \\
\hline & Monovarietal & 112 & 47.1 & 132 & 49.1 & 126 & 48.5 & 370 & 48.1 \\
\hline \multirow{15}{*}{$\begin{array}{l}\text { Farm and production process } \\
\text { attributes }\end{array}$} & Olive oil prod $<35 \mathrm{hl}$ & 85 & 35.7 & 106 & 39.4 & 93 & 35.8 & 390 & 37.0 \\
\hline & Olive oil prod 35-134 hl & 74 & 31.1 & 80 & 29.7 & 85 & 32.7 & 319 & 31.2 \\
\hline & Olive oil prod $135-235 \mathrm{hl}$ & 20 & 8.4 & 21 & 7.8 & 23 & 8.8 & 85 & 8.3 \\
\hline & Olive oil prod 236-335 hl & 10 & 4.2 & 16 & 5.9 & 17 & 6.5 & 59 & 5.5 \\
\hline & Olive oil prod > $335 \mathrm{hl}$ & 49 & 20.6 & 46 & 17.1 & 42 & 16.2 & 183 & 18.0 \\
\hline & $\begin{array}{l}\text { Hand picking and } \\
\text { beating }\end{array}$ & 118 & 49.6 & 142 & 52.8 & 130 & 50 & 390 & 50.8 \\
\hline & Farm olive oil mill & 123 & 51.7 & 130 & 48.3 & 126 & 48.5 & 379 & 49.4 \\
\hline & Cooperative & 24 & 10.1 & 23 & 8.6 & 20 & 7.7 & 67 & 8.7 \\
\hline & Purchased olives $>50 \%$ & 48 & 20.2 & 49 & 18.2 & 45 & 17.3 & 142 & 18.5 \\
\hline & $\begin{array}{l}\text { EVOO from organic } \\
\text { farming }\end{array}$ & 73 & 30.7 & 80 & 29.7 & 87 & 33.5 & 240 & 31.3 \\
\hline & Ecosustainability award & 155 & 65.1 & 184 & 68.4 & 185 & 71.2 & 524 & 68.3 \\
\hline & Farm ranking $80-84$ & 49 & 20.6 & 68 & 25.3 & 54 & 20.8 & 171 & 22.3 \\
\hline & Farm ranking $85-89$ & 84 & 35.3 & 84 & 31.2 & 93 & 35.8 & 261 & 34 \\
\hline & Farm ranking 90-94 & 67 & 28.2 & 68 & 25.3 & 60 & 23.1 & 195 & 25.4 \\
\hline & Farm ranking 95-100 & 40 & 16.8 & 49 & 18.2 & 53 & 20.4 & 142 & 18.5 \\
\hline \multirow[t]{5}{*}{ Geographic al origin attributes } & North & 31 & 13 & 32 & 11.9 & 26 & 10 & 89 & 11.6 \\
\hline & Center & 130 & 54.6 & 153 & 56.9 & 156 & 60 & 439 & 57.2 \\
\hline & South & 77 & 32.4 & 84 & 31.2 & 78 & 30 & 239 & 31.2 \\
\hline & Gls & 92 & 38.7 & 85 & 31.6 & 85 & 32.7 & 262 & 34.2 \\
\hline & Observations & 238 & 100 & 269 & 100 & 260 & 100 & 767 & 100 \\
\hline
\end{tabular}

Source: our elaborations on FLOS OLEl (editions 2013, 2014, and 2015)

part of the distribution (90th quintile), we find very high values ( $>33$ or $>36$ Euros/lt. depending on the year). These values confirm that the guide looks at extremely sophisticated market segment.

The independent variables included in the model are the following (Table 2):

2. Variables related directly to product $(M)$ are the following: two variables concern olive varieties: (i) one assesses whether the oil is made out of more than one variety all milled together $(51.9 \%)$ or if it is made with only one variety $(48.1 \%)$, that is, the socalled mono-varietal olive oil; (ii) the other variable allows distinguishing oils made by local olive varieties (67.7\%) from oils made by more common, largely widespread varieties (32.3\%). One more variable expresses the intensity of the fruity flavoring and is graded in three levels: light ( $8.1 \%$ of the oil reviewed), medium $(76.0 \%)$, and intense (15.9\%). The last variable in the group indicates bottle size: $500 \mathrm{ml}$ (is the most 
frequent with $90.6 \%$ of the oils reviewed), $250 \mathrm{ml}(6.1 \%)$, and $750 \mathrm{ml}$ (3.3\%). This, again, confirms that these oils are of very high quality as, in the Italian market, larger bottles prevail in less sophisticated markets.

3. A large group of variables (Pro) describes features of the producer and of the production process. Starting with the size of the producer, this is expressed in terms of volumes of the total olive oil production. Five size ranges are built from the smallest, with less than $35 \mathrm{hl}$ (37\%), to the largest ones with over $335 \mathrm{hl}$ (18\%). One dummy variable acknowledges whether the olives are milled on-farm (49.4\%) while another one distinguishes olive oils produced by coops $(8.7 \%)$. More directly linked to the production process, there are two more variables: one assesses farms that harvest olives by hand (50.8\%); the other distinguishes organic olive oils (31.3\%). Other variables are built based on the producer evaluation as assessed by the guide. The evaluations are expressed on a 100-point scale, where 80 is the minimum threshold to be allowed in the guide. The whole sample can be summarized in four classes of evaluation: good producers (those scoring 80-84) are 22.3\%; very good (85-89) are $34 \%$ of the reviewed ones; $25.4 \%$ of the total sample is evaluated as excellent (90-94); and the last, the top producers, defined as the outstanding ones (95-100), are 18.5\%. ${ }^{4}$ One more variable indicates whether the farms received the "Flos Olei Eco-sustainability Award" (68.3\%).

4. Ar represents a few variables indicating the production areas. First, three macroareas are depicted, North (11.6\%), Centre (57.2\%), and South, including the big islands: Sicily and Sardinia (31.2\%). Second, a dummy variable assesses whether the origin is certified by the PDO-PGI European certification scheme, where the two are kept together $(34.2 \%)$ as opposed to the non-certified products. The geographical origin certified by this scheme is defined at a narrower level, comprising groups of municipalities, provinces, or, at most, entire regions. Due to the small number of EVOO reviewed for each PDO-PGI, the model could not assess the value of each individual PDO-PGI (i.e., EVOO Sabina PDO as compared to EVOO Umbria PDO) but only the value of the certification tout court (PDO-PGI EVOO as compared to non-PDO-PGI EVOO) has been tested.

\section{Results of the regressions}

Table 3 reports the results for annual OLS estimations, pooled OLS, and the panel regression estimates both with fixed and random effects, while the discussion of the results is based essentially on the RE coefficient estimates. This allows us to focus on time-varying features and to check for the emergence of new trends in product specifications in this high market segment which serves sophisticated consumers usually leading the market.

The fit of the regression is similar for annual and pooled OLS and RE estimates as it is shown by the $R^{2}$ values that span from 0.32 to 038 . Only the FE estimate presents lower $R^{2}$ due to the characteristic of this approach which does not permit to estimate the coefficients of the time-invariant variables. Overall, these are quite good values for the hedonic price studies (e.g., Schamel and Anderson 2003 and Gustafson et al. 2016), indicating, however, that olive oil market is well sophisticated with many more attributes potentially influencing the market values.

The main findings in this study suggest that at least a few variables within each of the three different groups (product features, producer and production process characteristics, and the production area) are significantly linked to the price. 


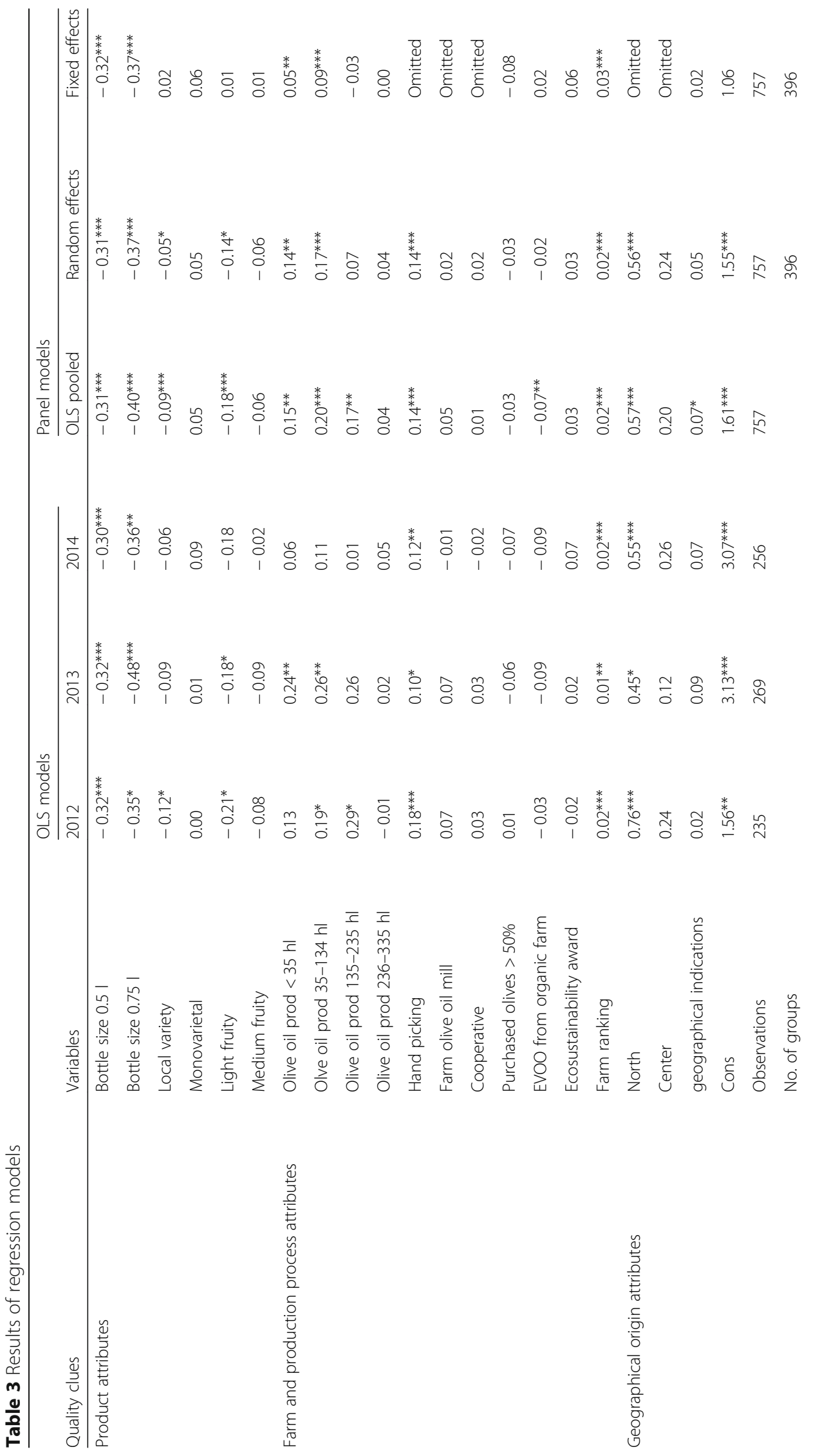




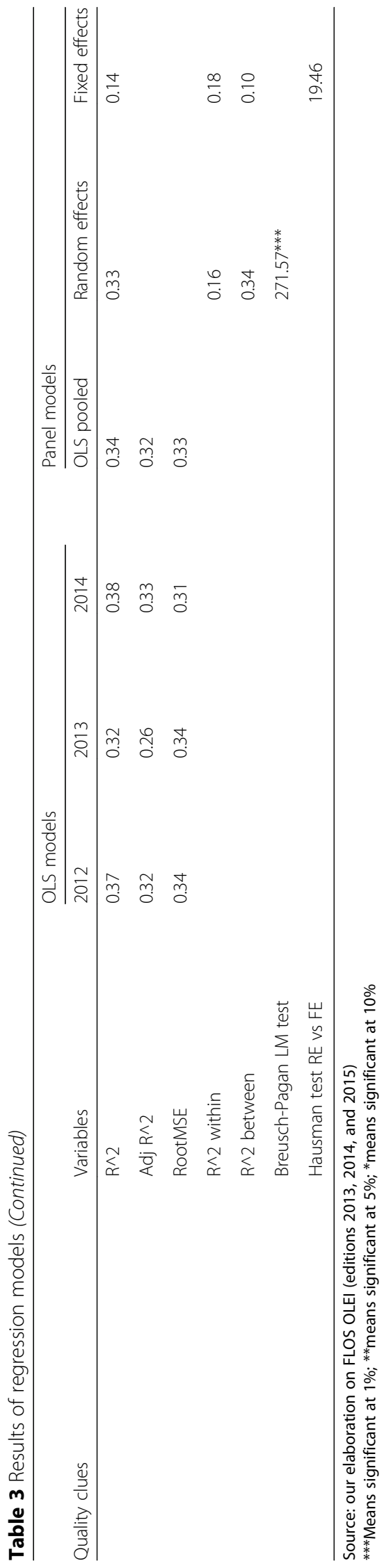


Starting with product variables $(M)$, not surprisingly, the estimates indicate that the bottle size is the most influential feature, with about one third price reduction when switching from 0.250 to $0.500 \mathrm{ml}$ and an even larger gap (-37\%) with $0.750 \mathrm{ml}$ bottles. The other relevant variable in this group is taste, with intense fruity oils that gain around $+14 \%$ more compared with the light fruity ones while price differentials are not significant for the medium fruity oils. Specific olive varieties used for making oil are also effective in terms of generating a PP with local varieties less appreciated than nonlocal ones and monovarietal oils preferred to the ones made using blends of varieties. While none of these results is statistically significant in the OLS models, it is worth noticing that data suggest a positive time trend for monovarietal oils, with significant coefficients in the RE model. This result is in line with previous works exploring different datasets (Cacchiarelli et al. 2016). As for the presence of local olive varieties, this generates a significant PP only in 2012.

Looking at the variables in the second group (Pro), we find that a few quality clues are associated to wide increases in prices while the impact of some others is much more limited. Moreover, some of these impacts change over time. In particular, evaluations given by the guide are associated with large PP as the price increases by $2 \%$ for each additional score received (i.e., oils ranked 85, other things being equal, get a price $2 \%$ higher than oils scored 84); the results are well aligned with those found in previous works (Benfratello et al. 2009).

Also, producer's size has quite a high impact on price, with an average of $14-17 \% \mathrm{PP}$ gained by smaller producers over the larger ones. Producers that chose to pick olives manually can enjoy a significant PP of around 14\%, while neither the presence of an on-farm mill nor the practice to buy olives on the market in significant amounts seem to associate with price differentials. The same holds for organic certification as well as for the Eco-sustainability Award: both seem not to have a systematic impact on price or even show a slightly negative impact ( $-7 \%$ in OLS pooled model) compared to conventional methods. It is worth to pinpoint that these results are not aligned to those of previous works (Cacchiarelli et al. 2016; Corsi and Strøm 2013) where consumers appreciate organic EVOO. Overall, this discrepancy indicates a sharp market segmentation with respect to this feature with consumers in high market segments that seem to value more features directly related to the producer than official third party certifications (see below the results for the PDO/PGI certification).

Coming to the last group of variables, those related to product origin, we find that the macro-region has a high impact on price with more than 50\% PP for EVOOs from Northern regions and 24\% PP from Central regions, compared to those from Italian Southern areas. On the contrary, the certification of origin has no significant effects in terms of price. This result is in line with those of the other works made in traditionally producing countries: Cabrera et al. (2015) for the Spanish market; Aprile et al. (2012), van der Lans et al. (2001), and Scarpa and Del Giudice (2004) for Italy; and Fotopoulos and Krystallis (2001) for Greece. Such values confirm that so far in the olive oil traditional markets, the certification of origin plays a minor role compared to the wine sector where the certification of origin is a relevant quality clue, even if its impact is diverse in different market segments (Cacchiarelli et al. 2016). Results in newer and further markets may be, of course, well different, as showed by Carlucci et al. (2014) who have analyzed the market EVOO sold in virtual shops. 


\section{Conclusions}

Traditionally, Italian olive oil market was based on three major divides: (i) EVOO vs non-EVOO; (ii) local informal markets where consumers had basically long-lasting knowledge and relationships with the producers vs more industrial standardized production; and (iii) the place of production, basically defined at the regional level, where the regional markets were quite neatly separated and with the Southern regions less reputed, on average, than the other ones (North and Centre).

In recent years, olive oil is becoming more sophisticated with a connotation as a hedonic good and with a number of emerging quality features which affect consumers' choices. Many quality attributes are progressively segmenting, both horizontally and vertically, the market. Furthermore, while the local/regional dimension of consumption still remains relevant, the search for novelty is significantly widening this market. Some of these quality characteristics are experience or even credence and require a lot of information to be provided at a different level of the supply chain. In this scenario, producers engage a quality-based competition, especially in high market segments, and winners get market shares and significant price premiums.

In this study, a hedonic price approach was applied to the Italian EVOO high market segment. Data come from one of the major Italian olive oil guides Flos Olei that only considers very high-quality oils mainly from small to medium producers. Focusing on this segment allows highlighting behaviors and trends that likely anticipate tendencies that will become more common and generalized in the wider market in the near future (Wiedmann et al. 2007). Besides, the richness of the dataset and the methodology used for the estimations allows for getting additional insights on the relationship between the selected characteristics and EVOO prices with respect to the few existing works on the topic.

Overall, our results confirm that, in high market segments, consumers actively search information on quality-beside considering claims disclosed in products' label or by certifications and official quality schemes-via a more direct relation with the producer and looking at more "hidden," or less easy to assess, clues such as the kind of olives, the different aspects of the production process, the size and nature of the producer, and the relevant features of the production area.

In particular, the area of production still remains one key factor with a lower PP associated to olive oils from the South that still suffer, on average, from a lower reputation. However, in other (lower) market segments, the gap between production areas is presumably higher than what we found in Flos Olei selection (ISMEA 2016).

The size of the bottle shows the expected inverse and strong relation with price, with larger bottles that are paid less than smaller ones. We also showed that, in this market segment, olive oils with intense flavorings worth significantly more than delicate oils. This is coherent with a demand for high-quality EVOOs to be used as a raw condiment rather than for cooking, as for such uses an intense flavor is usually more appreciated than a more neutral taste.

The model also highlights some new emerging tendencies for a good that is assuming more and more the features of a hedonic good. Among these trends, it is worthwhile to recall the emerging role of the guides and experts' evaluations which, in an increasingly sophisticated market, provide consumers with big amounts of complex information useful for orienteering and doing informed choice. This suggests that participating in 
prizes as well as being embedded in a net of social relationships and eventually being reviewed by experts are all relevant elements of a marketing strategy aimed at gaining visibility and higher value. This is particularly important for smaller producers that cannot obtain visibility due to the small volumes sold. The higher value paid for EVOO from small producers is probably connected to the idea that scarce/rare products tend to be more precious and, hence, more valuable (Wiedmann et al. 2007 and 2009). Besides, it is commonly believed that small producers follow more traditional technologies including manual harvesting, and are overall keener about quality.

It is also worth to pinpoint that results of the panel regression indicate the emerging appreciation for monocultivar EVOOs. Using monocultivar olives is a tool for enhancing the raw material, differentiating supply, and providing novelties to exigent consumers (García-González and Aparicio 2010).

Last, it is worth to recall that the analysis shows how the European quality certifications are not well established and valued by Italian EVOO consumers; this is at least true in this high market segment where consumers seem to value more other clues directly related to the production process and to the production area.

\section{Endnotes}

${ }^{1}$ Preliminarily, the selection between the different functional forms was restricted to the linear and log-linear functional form in order to allow an interpretation of the estimated parameters in terms of price elasticity (Brentari and Levaggi 2010). The linear specification of the functional form was rejected for the years 2013 and 2014, while for 2012, it was not possible to detect the missed specification. Hence, the log-linear specification was employed among all the models.

${ }^{2}$ Specifically, Flos Olei asks the producers to indicate in which price class their product falls, out of 11 proposed levels. The proposed levels are as follows: $2,01-4 ; 4,01-6 ; 6$, 01-8; 8, 01-10; 10, 01-12; 12, 01-15; 15, 01-18; 18, 01-22; 22, 01-26; 26, 01-30; and 30, 01-35 Euros). Subsequently, these values are randomly checked by the editors.

${ }^{3}$ It is necessary to underline that using the regression values obtained, transforming the averages of the original price classes (those released by the guide) clearly introduces a distortion (it is a linear transformation of values of which the actual distribution is unknown) and reduces the actual variability of prices. This reduction of variability in the explained variable partly hides the impacts of the explaining variables. However, in a comparative perspective, results of the analysis hold and allow to assess which variables are more/less influential (see the "Results and discussion" section for the comments).

${ }^{4}$ For each farm, only one olive oil item is selected even if the farm supply is diversified and includes several labels and/or different specific lines of production. The evaluation is given taking into account several factors that refer to the entire production of olive oil and to the farm. Aspects related to product quality, including quality stability over time, are considered, together with the vertical integration of the whole process that is considered valuable for traceability and full information on the consumer side. Also a price/quality ratio is taken into account for the scoring. 


\section{Competing interests}

The authors declare that they have no competing interests.

\section{Publisher's Note}

Springer Nature remains neutral with regard to jurisdictional claims in published maps and institutional affiliations.

Received: 10 May 2017 Accepted: 16 March 2018

Published online: 17 April 2018

\section{References}

AGER, (2016) Filiera olivicola. Analisi di scenario 2015-2016. Downloaded 29/09/2017 from: http://www.unaprol.it/ images/stories/Scenari\%20di\%20economici/Filiera\%20olivicola_Analisi\%20di\%20scenario\%202015-2016.pdf

Aprile MC, Caputo V, Nayga RM Jr (2012) Consumers' valuation of food quality labels: the case of the European geographic indication and organic farming labels. Int J Consum Stud 36(2):158-165 https://doi.org/10.1111/ j.1470-6431.2011.01092.x

Benfratello L, Piacenza M, Sacchetto S (2009) Taste or reputation: what drives market prices in the wine industry? Estimation of a hedonic model for Italian premium wines. Appl Econ 41(17):2197-2209 https://doi.org/10.1080/ 00036840701222439

Brentari E, Levaggi R. (2010) Hedonic price for the Italian red wine: a panel analysis. Downloaded 29/09/2017 from: http://www.wine-economics.org/aawe/wp-content/uploads/2013/07/69-Reims2009-Brentari-Levaggi.pdf

Breusch TS, Pagan AR (1980) The Lagrange multiplier test and its applications to model specification in econometrics. Rev Econ Stud 47:239-253

Cabrera ER, Arriaza M, Rodríguez-Entrena M (2015) Is the extra virgin olive oil market facing a process of differentiation? A hedonic approach to disentangle the effect of quality attributes. Grasas Aceites 66(4):105 https://doi.org/10.3989/ gya.0253151

Cacchiarelli L, Carbone A, Esti M, Laureti T, Sorrentino A (2016) Assessing Italian wine quality and prices: de gustibus non disputandum est. Br Food J 118(5):1006-1024

Cacchiarelli L, Carbone A, Laureti T, Sorrentino A (2014) The value of quality clues in the wine market: evidences from Lazio, Italy. J Wine Res 25(4):281-297

Cacchiarelli L, Carbone A, Laureti T, Sorrentino A (2016) The value of the certifications of origin: a comparison between the Italian olive oil and wine markets. Br Food J 118(4):824-839

Carbone A, Caswell J, Galli F, Sorrentino A (2014) The performance of protected designations of origin: an ex post multi-criteria assessment of the Italian cheese and olive oil sectors. J Agric Food Ind Org 12(1):121-140

Carlucci D, De Gennaro B, Roselli L, Seccia A (2014) E-commerce retail of extra virgin olive oil: an hedonic analysis of Italian SMEs supply. Br Food J 116(10):1600-1617

Corsi A, Strøm S (2013) The price premium for organic wines: estimating a hedonic farm-gate price equation. J Wine Econ 8(01):29-48

Costanigro M, McCluskey JJ, Goemans C (2010) The economics of nested names: name specificity, reputations, and price premia. Am J Agric Econ 92(5):1339-1350 https://doi.org/10.1093/ajae/aaq065

De Gennaro B, Roselli L, Medicamento U (2009) Evoluzione Degli Scambi Commerciali Dell'italia Nel Mercato Mondiale Degli Oli Di Olive. Agri Regioni Europa 5(17):78-82

Del Giudice T, Cavallo C, Caracciolo F, Cicia G (2015) What attributes of extra virgin olive oil are really important for consumers: a meta-analysis of consumers' stated preferences. Agric Food Econ 3(1):1-20 https://doi.org/10.1186/ s40100-015-0034-5

Delgado C, Guinard JX (2011) How do consumer hedonic ratings for extra virgin olive oil relate to quality ratings by experts and descriptive analysis ratings? Food Qual Prefer 22(2):213-225 https://doi.org/10.1016/j.foodqual. 2010.10.004

Dentoni D, Reardon T (2010) Small farms building global brands through social networks. J Chain Netw Sci 10(3):159-171

Diotallevi F (2010) The analysis of the demand for extra virgin olive oil in Italy: application of the aids model, vol 2010. Phd Thesis, Rural and Sustainable Development, XXi Cicle, Unversity of Perugia - Department of Economics and Food sciences Available at https://doi.org/10.2139/ssrn.2185678

Fotopoulos C, Krystallis A (2001) Are quality labels a real marketing advantage? J Int Food Agri Bus Mark 12:1-22 https://doi.org/10.1300/j047v12n01_01

García-González DL, Aparicio R (2010) Research in olive oil: challenges for the near future. J Agric Food Chem 58(24):12569-12577

Gázquez-Abad JC, Sánchez-Pérez M (2009) Factors influencing olive oil brand choice in Spain: an empirical analysis using scanner data. Agribusiness 25(1):36-55. https://doi.org/10.1002/agr.20183

Greene WH (2003) Econometric analysis. Pearson Educ Ind

Gujarati DN (2004) Basic econometrics, Fourth edn. The McGraw-Hill Companies

Gustafson CR, Lybbert TJ, Sumner DA (2016) Consumer sorting and hedonic valuation of wine attributes: exploiting data from a field experiment. Agric Econ 1(47):91-103

Hassan D, Mornier-Dilhan S (2002) Signes de qualité et qualité des signes: une application au marchè du camambert. Cahiers d'economie et sociologie rurales 65:23-36

Hausman JA (1978) Specification tests in econometrics. Econometrica:1251-1271

Hsiao C (2007) Panel data analysis—advantages and challenges. TEST 16(1):1-22

IOOC: International Olive Oil Council (2016) International production, exports and imports of olive oil and classification and definitions of olive oils. Retrieved from http://www.internationaloliveoil.org

Ismea (2016) National and regional production and prices of the Italian olive oil. Retriewed from www.ismea.it

Karipidis P, Tsakiridou E, Tabakis N (2005) The Greek olive oil market structure. Agric Econ Rev 6(1):64-72 
Marchini A, Diotallevi F, Paffarini C, Stasi A, Baselice A (2015) Visualization and purchase: an analysis of the Italian olive oil grocery shelves through an in-situ visual marketing approach. Qual Mark Res Int J 18(3):346-361

Matthäus B, Spener F (2008) What we know and what we should know about virgin oils ? A general introduction. Eur J Lipid Sci Technol 110:597-601 https://doi.org/10.1002/ejlt.200800118

Olei F (2013) Guida al mondo dell'extravergine. 2013. E.V.O. srl Italy

Olei F (2014) Guida al mondo dell'extravergine. 2014. E.V.O. srl Italy

Olei F (2015). Guida al mondo dell'extravergine. 2015. E.V.O. srl Italy

Paroissien E, Visser M (2018) The causal impact of medals on wine producers' prices and the gains from participating in contests. AAWE 223:1-25 Retrieved from: http://www.wine-economics.org/dt_catalog/aawe-working-paper-no223-economics/

Romo Munoz R, Lagos Moya M, Gil JM (2015) Market values for olive oil attributes in Chile: a hedonic price function. Br Food J 117(1):358-370. https://doi.org/10.1108/BFJ-01-2014-0009

Roselli L, Carlucci D, Gennaro BC (2016) What is the value of extrinsic olive oil cues in emerging markets? Empirical evidence from the US e-commerce retail market. Agribusiness

Rosen S (1974) Hedonic prices and implicit markets: product differentiation in pure competition. J Polit Econ 82(1):34 https://doi.org/10.1086/260169

Sandalidou E, Baourakis G, Siskos Y (2002) Customers' perspectives on the quality of organic olive oil in Greece: a satisfaction evaluation approach. Br Food J 104:391-406 https://doi.org/10.1108/00070700210425787

Scarpa R, Del Giudice T (2004) Market segmentation via mixed logit: extra-virgin olive oil in urban Italy. J Agric Food Ind Organ 2(1):1-18 https://doi.org/10.2202/1542-0485.1080

Schamel G (2006) Geography versus brands in a global wine market. Agribusiness 22(3):363-374. https://doi.org/ 10.1002/agr.20091

Schamel G, Anderson K (2003) Wine quality and varietal, regional and winery reputations: hedonic prices for Australia and New Zealand. Econ Rec 79(246):357-369

Smith RA, McKinney CN, Caudill SB, Mixon FG (2016) Consumer ratings and the pricing of experience goods: hedonic regression analysis of beer prices. Agric Food Econ 4(1):24

Stasi A, Diotallevi F, Marchini A (2012) Strategies and profitability in the market price of oil extra virgin olive oil: a model analysis through the scanner data. Riv Econ Agrar 67(1):69-88

Thrane C (2004) In defence of the price hedonic model in wine research. J Wine Res 25(2):123-134

Van der Lans I, Van Ittersum K, De Cicco A, Loseby M (2001) The role of the region of origin and EU certificates of origin in consumer evaluation of food products. Eur Rev Agric Econ 28(4):451-477

Wiedmann KP, Hennigs N, Siebels A (2007) Measuring consumers' luxury value perception: a cross-cultural framework Acad Mark Sci Rev 7(7):333-361

Wiedmann KP, Hennigs N, Siebels A (2009) Value-based segmentation of luxury consumption behavior. Psychol Mark 26(7):625-651

Submit your manuscript to a SpringerOpen ${ }^{\odot}$ journal and benefit from:

- Convenient online submission

- Rigorous peer review

- Open access: articles freely available online

High visibility within the field

Retaining the copyright to your article

Submit your next manuscript at $>$ springeropen.com 